\title{
Why narrative?
}

\section{John Launer}

If you have been reading medical journals regularly over the last few years, you will almost certainly have noticed that the word "narrative" has been appearing more and more often. You may even have come across articles referring to "narrative-based medicine" or simply "narrative medicine". "What exactly is a narrative and what is narrative medicine all about?

A narrative is quite simply a story-no more and no less. As Aristotle said, a story has a beginning, a middle and an end. It also has other common features including a character or characters, a sense of time, a degree of suspense as it unfolds, and some kind of plot. It can be spoken or written, and it can be very short indeed (as in "I've just fallen down and cut my knee") or extremely long. The only reason for preferring the word narrative to the word story is probably because it is connected to the verb "to narrate". Hence it conveys more impression of a process and it is easier to inflect into a range of other words such as narrating and narration.

Stories are universal and as old as human civilisation. However, it was only in the 20th century that a wide range of thinkers started to observe that we all speak, think and experience our lives in narrative form. In other words, we receive the sensory data that comes our way as individuals or as groups, and we instinctively reformulate these into the form of a story. As the philosopher Charles Taylor has written: "We understand ourselves inescapably in narrative". Or, to quote the psychologist Jerome Bruner: "To be in a culture is to be bound in a set of connecting stories".

Traditionally people have always thought of a story as something told by just one person, but, as modern commentators have realised, it needs at least two. A written story requires both a writer and a reader. Spoken stories depend on the presence of the storyteller and at least one listener, who usually contributes to the development of the narrative through questions, comments and other interjections. The qualities of the listener can of course make a huge difference to how the

Correspondence to: Dr John Launer, London Deanery, Stewart House, London WC1B 5DN, UK; jlauner@ londondeanery.ac.uk story gets told-something of particular importance in medicine.

\section{WEAVING FACTS TOGETHER}

It is hard to exaggerate the influence that the study of narrative has now had in almost every academic field. In virtually every area of scholarship, the focus has moved from the study of facts to looking at how people weave these facts together into stories, and at how the stories themselves change as they are told and heard. Inevitably, such ideas have come to have a considerable influence in medicine as well. There are all kinds of people nowadays who describe themselves as having an interest in narrative medicine-although they don't necessarily all share the same beliefs. Broadly speaking, their interests cover the following:

- Studying literary texts, including great novels and poetry, and looking at how these can heighten our sensitivity as doctors

- Studying stories about personal illness, written by historical or contemporary patients, or by doctors who have also been patients

- Encouraging doctors and medical students to write stories and poems, as a way of expressing and learning about their professional experiences

- Carrying out research into how patients describe their illnesses when talking to doctors or to each other

- Examining the way that doctors talk to each other about their work (or write about it), and how they "construct" medical knowledge in this way

- Examining the way that patients and doctors talk to each other and hence negotiate between their different accounts of illness

- Training doctors and medical students to be more attentive to patients' stories and to collaborate with them in creating more satisfactory ones

From this list it should be clear that narrative medicine converges with many other disciplines. These include medical ethics, anthropology and sociology, as well as medical humanities. Narrative medicine also overlaps with several aspects of medical training including communication skills and professionalism. Not surprisingly, people interested in narrative medicine are often interested in other theories concerned with human relationships, including systems theory, complexity and psychoanalysis. For all these reasons, one could be forgiven for questioning whether narrative medicine is really one identifiable approach with established boundaries and a clear definition, or whether it is simply a fashionable flag of convenience for a variety of folk who may have little in common except a liking for words.

\section{NARRATIVE AND EVIDENCE}

My own view is that there are at least two concepts that distinguish narrative medicine and that hold it together coherently in all its different forms. One of these is the way in which narrative medicine claims legitimacy for individual stories as a counterpoise to evidence-based medicine, and as an essential complement to evidence. Narrative medicine, in other words, reasserts the importance of lived experience, and the expression of that experience, in the face of the dominant intellectual voice in modern medicine-a voice that often creates the impression that only collectivised, abstract measurements can convey truths or carry meaning. At the same time, everyone writing about narrative medicine has emphasised that narrative is not a substitute for evidence, nor does it stand in opposition to it. Instead, as the American scholar Rita Charon argues, it calls upon us to recognise "the narrative features of all data and the evidentiary status of all clinical text". ${ }^{3}$

The other unifying concern of narrative medicine is with "narrative competence". Narrative competence encompasses skills for listening and expression, but most of all for empathic interaction through language. Writing recently in the Permanente Journal, Vera Kalitzkus and Peter Matthiessen list the essential skills for narrative competence as follows: ${ }^{4}$

- Sensitivity to the context of the illness experience and the patient-centred perspective

- Establishing a diagnosis in an individual context instead of merely in the context of a systematic description of the disease and its aetiology

- Narrative communication skills such as exploring differences and connections, hypothesising [and] sharing power

\section{- Self-reflection}

Seen in this light, narrative medicine appears as something rather different from a portmanteau definition covering various 
other schools of thought. Instead (to change the metaphor) it is more like a foundation offering moral and practical underpinning to every aspect of being a doctor.

\section{SHARED STORIES}

Narrative isn't everything, nor does the world exist through words alone. Although there are some theorists who claim that all knowledge and all understanding are of a purely linguistic nature, this position will be of little appeal to doctors who deal on an everyday basis with the realities of disease and disability. Equally, few doctors will be in sympathy with the lazy contemporary practice of describing just about any idea or movement as a narrative-for example, "doctors usually subscribe to a narrative of doing good" or "the grand narrative of capitalism". At the same time, most of us will have little difficulty in recognising that the stories we acquire from childhood onwards, and later hear from our patients or share with our colleagues, lie at the heart of our personal and professional lives. Perhaps we need more than narrative competence for our work to flourish, but it certainly cannot do so without it.

Competing interests: None.
Postgrad Med J 2009:85:167-168. doi:10.1136/pgmj.2009.079871

\section{REFERENCES}

1. Greenhalgh T, Hurwitz B, eds. Narrative based medicine: discourse and dialogue in medical practice. London: BMJ Books, 1998.

2. Charon R. The patient-physician relationship. Narrative medicine: a model for empathy, reflection, profession and trust. JAMA 2001;286:1897-902.

3. Charon R, Wyer P, for the NEBM Working Group. Narrative evidence based medicine. Lancet 2008;371:296-7.

4. Kalitzkus V, Matthiessen P. Narrative-based medicine: potential, practice and pitfalls. The Permanente Journal 2009;13:80-6. http://xnet.kp.org/ permanentejournal/winter09/narrativemedicine.html (accessed 1 Feb 2009). 